\title{
Detection of Pesticide Thiram in Plant Leafs Using Voltammetric at Nanotube Electrode
}

\author{
Chang-Hyun Lee* , Suw-Young Ly ${ }^{1)}$ \\ Division of General Education, Pyeongtaek University, Gyeonggi-do 405-701, Korea \\ ${ }^{1)}$ Biosensor Research Institute, Seoul National University of Technology, Seoul 139-743, Korea \\ (Manuscript received 7 September, 2010; revised 1 November, 2010; accepted 22 November, 2010)
}

\begin{abstract}
Voltammetric diagnostics of pesticide thiram was studied in plant leafs in vivo fluid with DNA immobilized on a carbon nanotube electrode (DCE). Sensor properties of carbon nanotube (CE) and DNA immobilized nanotube were compared. DCE was more effective than $\mathrm{CE}$ in target detecting. The parameters such as $\mathrm{pH}$ strength, stripping accumulation, amplitude, and increment potential were examined to find the optimum condition for detection of pesticide thiram in a sesame leaf. The optimized conditions were as follows $550 \mathrm{~Hz}$ frequency, $0.15 \mathrm{~V}$ amplitude, $0.005 \mathrm{~V}$ increment potential, $-1.2 \mathrm{~V}$ initial potential, $4.78 \mathrm{pH}, 500 \mathrm{sec}$ accumulation time. Under optimum condition, the detection limit of thiram was attained at $0.01 \mathrm{ng} / \mathrm{L}$
\end{abstract}

Key Words : Stripping voltammetry, Pesticide, DNA nanotube, Sesami leaf, Thiram

\section{Introduction}

Recently, Korea is suffering from serious environmental problems caused by spraying pesticides. They are overused not only to increase agriculture production, but also to meet the demands of indiscreet country clubs. Today, about 1,300 kinds of pesticides are being manufactured as products and, out of these, about 430 kinds are used at farms. There are many ways to detect pesticides that cause serious problems in our environment.

The thiram(tetramethylthiuram disulfide, TMTD) is used mostly as a pesticide or a seed-sterilization for fruit trees and vegetables cabbages such as apples,

${ }^{*}$ Corresponding author : Chang-Hyun Lee, Division of General Education, Pyeongtaek University, Gyeonggi-do 405-701, Korea

Phone: +82-31-659-8384

E-mail: 1ch@ptu.ac.kr peaches, melons, vegetables cabbages, spinages, and carrots etc. in our farms. Korean farms have been using a pesticide thiram (tetramethylthiuram disulfide) long before because it prevents or reduces agricultural losses caused by pests, resulting in improved yield and greater availability of food, vegetable crops and seeds, as well as a vulcanizing agent in the rubber industry at a reasonable price, all year round (Cooper and Dobson, 2007; Cereser. et al., 2001). However, it has been reported that the trace of Thiram can cause Parkinson's disease, Alzheimer's disease (Gauthier et al., 2001), Paget's disease of bone (Leve, 2002), prostate and breast cancers (Landau-Ossondo et al., 2009), if it were exposed to people. It can also damage DNA (Garaj-Vrhovac and Zeljezic, 2000). For this reason, detection of pesticide thiram is important for human health. 
Many researches have been developed the various analysis methods such as opto fluidic ring resonator biosensor (Yang et al., 2008), flame photometric and mass spectrometric detection (Amirav and Jing, 1998), surface plasma resonance based fiber-optic sensor (Chand and Gupta, 2007), an amperometric micro-biodetector (Wu et al., 2009), $\mathrm{SPME} / \mathrm{SnO}_{2}$ gas sensor (Huang et al., 2004), liquid matrices by ion mobility spectrometry (Tuovinen et al., 2000), highperformance liquid chromatography (Huang et al., 2004), optical waveguide immunochemical sensors (Tuovinen et al., 2004), and label free optical immunoprobes (Perez-Ruiiz et al., 2005). Also included are an enzyme-based detection methodology (Lechunga et al., 1995), capillary zone electrophoresis (Brecht and Ganglitz, 1997), solid-phase microextraction, and gas chromatography with atomic emission detection (Ayyagari et al., 1995). Moreover an automated (Cheng et al., 2007), microextraction (Campillo et al., 2007), gas chromatography (KhaliliZanjani et al., 2008) and others have been developed as well.

The separation by spectrophotometric methods that have been developed are too complex and time consuming in the analysis. Several detecting methods are reported for chromatography, pollarography, NMR, atom adsorption spectrometery, X-ray diffraction spectrometery, Raman spectrometery, mass spectrometery, etc. However, these precision tools are extremely expensive and they are all imported from overseas. In addition, it is usually recommended to use 2-3 methods or sometimes 4 methods combined in order to get more accurate result, especially below the $\mathrm{ppb} \sim \mathrm{ppt}$ level.

Thus, voltammetric sensors such as polymeric enzyme electrodes (Dutta et al., 2008), gold nanoparticles at tyrosinase electrode (Kim et al., 2008), poly 3,4 ethylenedioxythiophene modified wall jet electrode (Manisankar et al., 2005), ferophthalocyanine chemically modified carbon paste electrode (Ciucu et al., 2003), polymer multiwalled carbon nanotubes modified glassy carbon electrode (Manisankar et al., 2008), and alumina sol gel sonogel carbon electrode (Zejli et al., 2008) have been searched, These electrodes are sensitive to detect pesticide, but the production of these electrodes are not easy and are time-consuming. However, an electrochemical analysis such as square wave anodic stripping voltammetry(SWASV) and cyclic voltammetry $(\mathrm{CV})$ is more powerful technique that can measure both metallic and nonmetallic organic elements quickly and precisely. It can also be used to detect very small-amount harmfull elements whether they are metallic or nonmetallic, and whether they are organic or inorganic.

It is considered that the electrochemical method employing CV and SWASV in a stripping mode is relatively less expensive and more sensitive than other voltammetric methods. Also, it can be used for detecting any harmful matetrials (Radi, 2005). Therefore, electrochemical instruments of voltammetric measurements with DNA immobilized on a carbon nanotube sensor (DCE) was developed and it was applied to detect a pesticide thiram in a sesame leaf.

\section{Materials and Methods}

\subsection{Apparatus, Reagents, and Procedure}

Electrochemical instruments of voltammetric measurements were used with the new system of Bioelectronics-1, which was first constructed at the authors' institute. The new version is a computerized handheld voltammetry with a $2.4 \mathrm{~V}$ potential range, a $2 \mathrm{~mA}$ current range, and a $10^{-12} \mathrm{~A}$ measuring current. The instrument size is similar to that of a typical cellular phone and can be used for the bioassay and sensor techniques for individual and laboratory application.

Carbon nanotube paste electrode (CE) was prepared using a $70 \%$ single walled carbon nanotube graphite powder and $30 \%$ mineral oil. DNA 
immobilized carbon nanotube paste electrode (DCE) was prepared using a $40 \%$ DNA (double-stranded calf thymus sigma reagent), $40 \%$ single-walled carbon nanotube graphite powder (Nanostructured \& Amorphous Materials, Inc.) and 20\% mineral oil. The mixture was homogenized in a mortar for 5 minutes. The small amount was inserted into a plastic needle type capillary tube $(1.5 \mathrm{~mm}$ in diameter and $5 \mathrm{~cm}$ in length) using a $0.5 \mathrm{~mm}$ diameter copper wire connected to the electrochemical workstation. A platinum counter of $0.5 \mathrm{~mm}$ diameter $\mathrm{Pt}$ wire, and a $\mathrm{Ag} / \mathrm{AgCl}$ reference electrode was used in experiment. Thiram was obtained from Aldrich (Steinheim, Germany). In living samples, $10.381 \mathrm{~g}$ of sesame leaf was grinded and got its juice. Juice was dissolved in $10 \mathrm{ml}$ distilled water. First, $0.1 \mathrm{ml}$ of sesame juice was spiked and $0.1,0.2$ and $0.3 \mathrm{ml}$ standard was spiked thereafter.

\section{Results and Discussion}

\subsection{Comparison of cyclic voltammetric sensor}

Fig. 1(a) shows the result of DNA immobilization effects. When a blank solution of $10 \mathrm{mg} / \mathrm{L}$ thiram was added, the peak currents of CE and DCE obtained $0.8015 \times 10^{-5} \mathrm{~A}$ and $0.1352 \times 10^{-5} \mathrm{~A}$, respectively. When 30 and $50 \mathrm{mg} / \mathrm{L}$ were added, those of CE attained $1.2443 \times 10^{-5} \mathrm{~A}$ and $1.656 \times 10^{-5}$ $\mathrm{A}$, respectively and those of DCE obtained $1.656 \mathrm{x}$ $10^{-5} \mathrm{~A}$ and $3.515 \times 10^{-5} \mathrm{~A}$. respectively It is shown that the slope of DCE is more sensitive than CE. Thus, it was chosen as a working electrode. Fig. 1(b) shows the $\mathrm{CV}$ effect. The thiram concentration was varied from $10 \mathrm{mg} / \mathrm{L}$ to $160 \mathrm{mg} / \mathrm{L}$. The peak current was observed at $-0.3 \mathrm{~V}$. Higher concentration caused a spike in the curves which were sensitive and sharp.

\subsection{SW stripping voltammetric parameters}

SW optimized conditions were examined using DCE. As shown in Fig. 2(a), the peak current obtained $10.98 \times 10^{-7} \mathrm{~A}$ at $\mathrm{pH} 2.18$. It decreased continuously and reached to $1.064 \times 10^{-7} \mathrm{~A}$ at $\mathrm{pH}$ 3.67 , then increased to $16.42 \times 10^{-7} \mathrm{~A}$ at $\mathrm{pH} 4.78$ and dropped again. Here maximum current was attained at $\mathrm{pH} 4.78$ and it was chosen as an optimum $\mathrm{pH}$ strength. Fig. 2(b) shows that the peak current increased continually as much time was given. The peak current finally reached to $23.48 \times 10^{-6} \mathrm{~A}$ at 500 $\mathrm{sec}$ and it was the maximum current. Accumulation time of $500 \mathrm{sec}$ was chosen as an optimum condition.

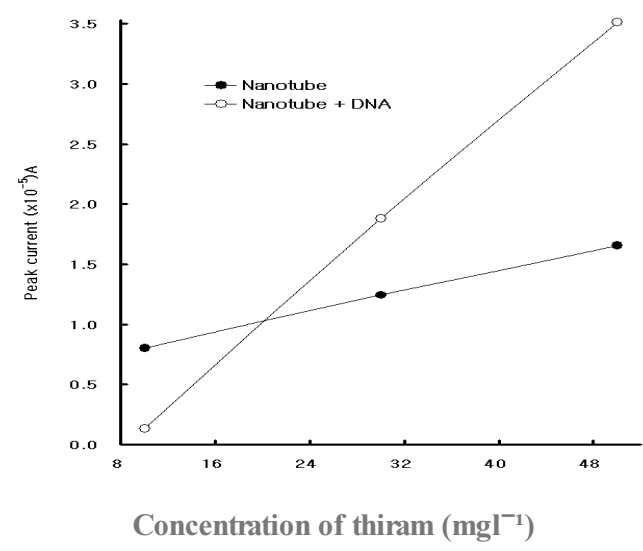

(a)

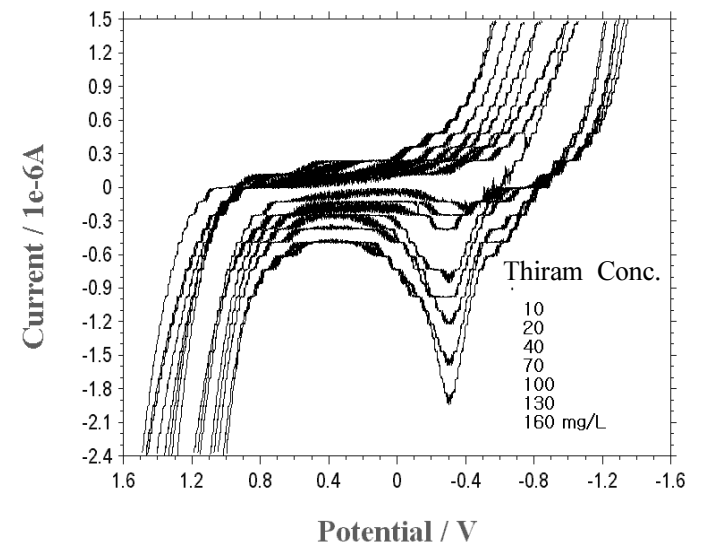

(b)

Fig. 1. (a) The comparison of two electrodes for 10,30 and $50 \mathrm{mg} / \mathrm{L}$ variation by $\mathrm{SW}$. (b) The $\mathrm{CV}$ scan using DCE ranges from 10 to $100 \mathrm{mg} / \mathrm{L}$ add in the $0.1 \mathrm{M}$ phosphate at $4.0 \mathrm{pH}$ electrolyte. 
Fig. 2(c) shows that the peak current obtained $3.416 \mathrm{x}$ $10^{-6} \mathrm{~A} 0.1 \mathrm{~V}$ and increased to $4.184 \times 10^{-6} \mathrm{~A}$ at $0.15 \mathrm{~V}$, then decreased. So $0.15 \mathrm{~V}$ was chosen as an optimum condition. Fig. 2(d) shows that the peak current obtained $5.065 \times 10^{-6} \mathrm{~A}$ at $0.005 \mathrm{~V}$. After that, it decreased quickly from $0.01 \mathrm{~V}$ to $0.025 \mathrm{~A}$. It increased again from $0.03 \mathrm{~V}$ to $0.035 \mathrm{~V}$, but it dropped again. Maximum current was attained at $0.005 \mathrm{~V}$. The other optimum parameters were $-1.2 \mathrm{~V}$ initial potential and $550 \mathrm{~Hz}$ frequency.

\subsection{Statistics and applications}

Under optimum conditions obtained from above section, low concentration of thiram was examined using $\mathrm{CV}$ and SW. Fig. 3(a) shows the CV voltammograms and their statistic equations in the range from 10 to $80 \mathrm{ng} / \mathrm{L}$ concentration. The peak current varied from $0.24 \times 10^{-6} \mathrm{~A}$ to $2.358 \times 10^{-6} \mathrm{~A}$.

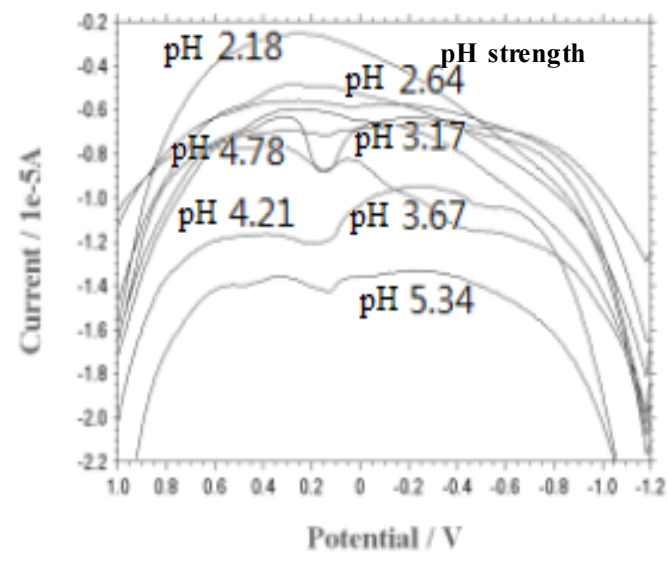

(a)

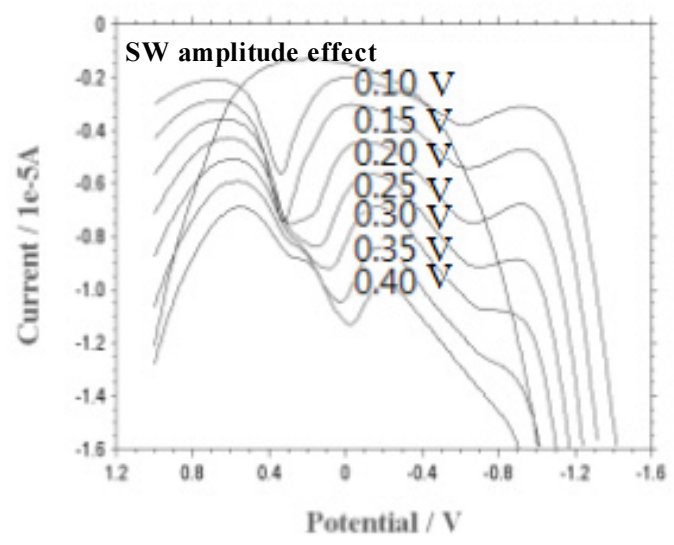

(c)

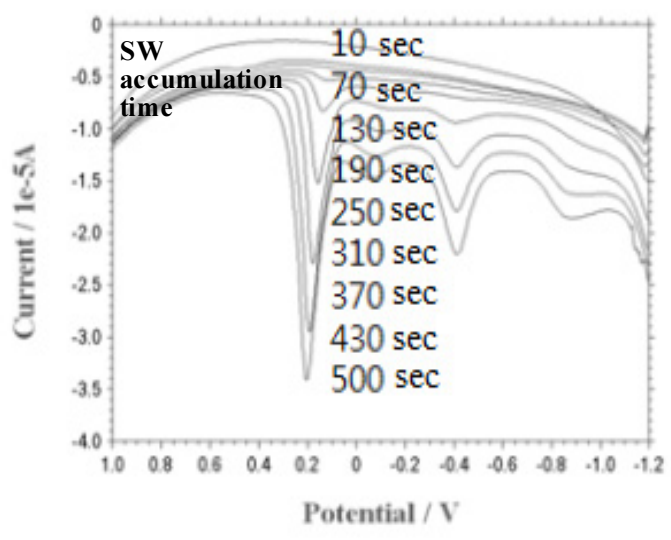

(b)

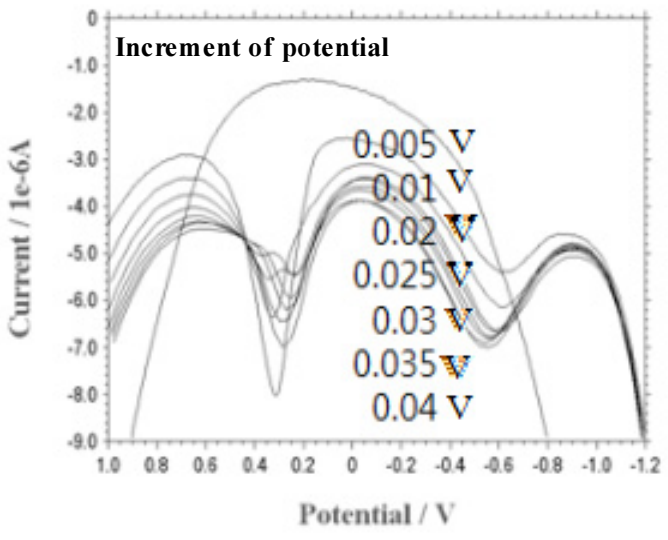

(d)

Fig. 2. The examination of various optimum conditions with SW using DCE (Initial potential: $-1.2 \mathrm{~V}$, frequency: $550 \mathrm{~Hz}$ ). (a) $\mathrm{pH}$ strength was varied from 2.18 to 6. (b) SW accumulation time was varied from 10 to $500 \mathrm{sec}$. (c) SW amplitude was varied from $0.1 \mathrm{~V}$ to $0.4 \mathrm{~V}$. (d) The increment potential was varied from $0.005 \mathrm{~V}$ to $0.04 \mathrm{~V}$. 
The peak were narrow and sharp and they spiked with higher concentration. Statistics equation of $\mathrm{CV}$ results was $\mathrm{y}=0.031 \mathrm{X}-0.168$ and $\mathrm{R}^{2}=0.993$. Moreover, $\mathrm{SW}$ results are better sensitive then CV, Fig. 3(b) illustrates the SW real voltammograms in the nano ranges of $0.01,0.02,0.03,0.04,0.05,0.06,0.07$ and $0.08 \mathrm{ng} / \mathrm{L}$ concentration. When $0.01 \mathrm{ng} / \mathrm{L}$ was spiked, $3.95 \times 10^{-6} \mathrm{~A}$ was obtained. The peak current increased quickly and reached to $12.12 \times 10^{-6} \mathrm{~A}$ at $0.08 \mathrm{ng} / \mathrm{L}$ concentration. The obtained linear equation was $\mathrm{y}=117 \mathrm{X}+3.143$ and precision was $\mathrm{R}^{2}=0.991$. It is considered that the voltammograms are sharp and usable for trace detection in any field. Under this condition, in vivo vitro detection and analytical detection limit was examined using a sesame leaf. Fig. 3(c) SW shows the result obtained for the sesame leaf by standard addition method. $10 \mathrm{ml}$ electrolyte blank, $0.1 \mathrm{ml}$ sesame juice, and 0.1, 0.2 and $0.3 \mathrm{ml}$ standard spike was added. The peak current was obtained of $0.6488,1.717,2.151$ and $2.348 \times 10^{-6} \mathrm{~A}$.

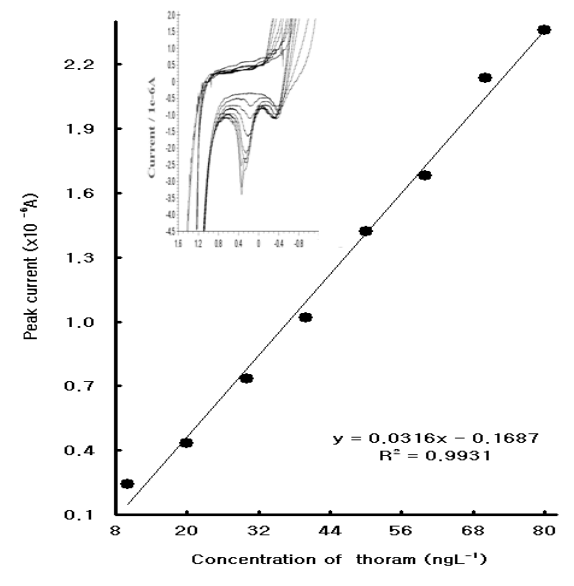

(a)

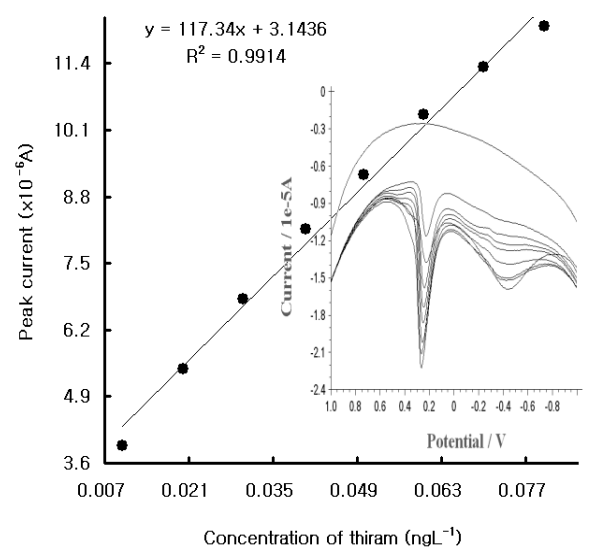

(b)

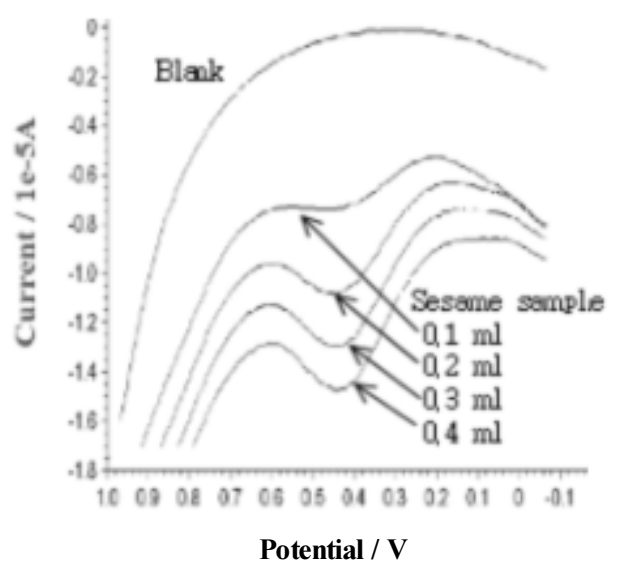

(c)

Fig. 3. (a) The CV effect using DCE in the nano ranges from 10 to $80 \mathrm{ng} / \mathrm{L}$. (b) The SW working ranges from 0.01 to 0.08 $\mathrm{ng} / \mathrm{L}$ variation using optimum parameters. (c) The result applied the developed sensor to a sesame leaf using standard addition method. 
Linear equation was $\mathrm{y}=0.5532 \mathrm{X}+0.333$ and precision was $R^{2}=0.885$. The pesticide thiram was detected in the sesame leaf, and its concentration calculated from this linear equation was $0.006 \mathrm{mg} / \mathrm{L}$.

\section{Conclusion}

Electrochemical instruments of voltammetric measurements with DNA immobilized on a carbon nanotube sensor (DCE) was developed and it was applied to detect a pesticide thiram in a sesame leaf. The optimized conditions were as follows $550 \mathrm{~Hz}$ frequency, $0.15 \mathrm{~V}$ amplitude, $0.005 \mathrm{~V}$ increment potential, $-1.2 \mathrm{~V}$ initial potential, $4.78 \mathrm{pH}$, and $500 \mathrm{~s}$ accumulation time. With these conditions, very high detection capacity was obtained. When this sensor was applied to the detection of pesticide in a sesame leaf with using standard addition method, this developed sensor could detect the pesticide thiram even in the low concentration. So, it could be considered that this analytical method can be expanded to the detection of the small amount of pesticide left in agricultural products and foods.

\section{References}

Aburuna, H. D., 1988, Coordination chemistry in two dimensions: chemically modified electrodes, ${ }_{2}$ Coord. Chem. Rev., 86, 135.

Amirav, A., Jing, H., 1998, Simultaneous pulsed flame photometric and mass spectrometric detection for enhanced pesticide analysis capabilities, Journal of Chromatography A, 814, 133-150.

Ayyagari, M. S., Kamtekar, S., Pande, R., Marx, K. A., Kumer, J., Tripathy, S. K., Kaplan, D. L., 1995, Biosensors for pesticide detection based on alkaline phosphatasecatalyzed chemiluminescence, Materials Science and Engineering: C, 2, 191-196.

Brecht, A., Gauglitz, G., 1997, Label free optical immunoprobes for pesticide detection, Analytica Chimica Acta, 347, 219-233.

Campillo, N., Pealver., M., Hernandez- Cordoba, M.,
2007, Pesticide analysis in herbal infusions by solid-phase microextraction and gas chromatography with atomic emission detection, Talanta, 71, 14171423.

Cereser, C., Boge, S., Parvaz, P., Revol, A., 2001, An evaluation of thiram toxicity on cultured human skin fibroblasts, Toxicology, 162, 89-101.

Chand, R. S., Gupta, B. D., 2007, Surface plasmon resonance based fiber-optic sensor for the detection of pesticide, Sensors and Actuators B, 123, 661-666.

Cheng, X., Wang, Q., Zhang, S., Zhang, W., He, P., Fang, Y., 2007, Determination of four kinds of carbamate pesticides by capillary zone electrophoresis with amperometric detection at a polyamidemodified carbon paste electrode, Talanta, 71, 10831087.

Ciucu, A. A., Negulescu, C., Baldwin, R. P., 2003, Detection of pesticides using an amperometric biosensor based on ferophthalocyanine chemically modified carbon paste electrode and immobilized bienzymatic system, Biosensors and Bioelectronics, 18, 303-310.

Cooper, J., Dobson, H., 2007, The benefits of pesticides to mankind and the environment, Crop Protection, 26, 1337-1348.

Dutta, K., Bhattacharyay, D., A. Mukherjee, A., Setford, S. J., Turner, A. P. F., Sarkar, P., 2008, Detection of pesticide by polymeric enzyme electrodes, Ecotoxicology and Environmental Safety, 69, 556-561.

Garaj-Vrhovac, V., Zeljezic, D., 2000, Evaluation of DNA damage in workers occupationally exposed to pesticides using single-cell gel electrophoresis (SCGE) assay Pesticide genotoxicity revealed by comet assay, Mutation Research, 469, 279-285.

Gauthier, E., Fortier, I., Courchesne, F., Pepin, P., Mortimer, J., Gauvreau, D., 2001, Environmental pesticide exposure as a risk factor for Alzheimer's disease: A case-control study, Environmental Research Section A, 86(1), 37-45.

Huang, X., Sun, Y., Meng, F., Liu, J., 2004, New approach for the detection of organophosphorus pesticide in cabbage using SPME/SnO2 gas sensor: principle and preliminary experiment, Sensors and Actuators B, 102, 235-240.

Khalili-Zanjani, M. R., Yamini, Y., Yazdanfar, N., 
Shariati, S., 2008, Extraction and determination of organophosphorus pesticides in water samples by a new liquid phase microextraction-gas chromatographyflame photometric detection, Analytica Chimica Acta, 606(2), 202-208.

Kim, G. Y., Shim, J. M., Kang, M. S., Moon, S. H., 2008, Optimized coverage of gold nanoparticles at tyrosinase electrode for measurement of a pesticide in various water samples, Journal of Hazardous Materials, 156, 141-147.

Landau-Ossondo, M., Rabia, N., Jos-Pelage, J., Marquet, L. M., Isidore, Y., Saint-Aime, C., M. Martin, M., Irigaray, P., Belpomme, D., 2009, ARTAC international research group on pesticides, Why pesticides could be a common cause of prostate and breast cancers in the French Caribbean Island, Martinique. An overview on key mechanisms of pesticide-induced cancer, Biomedicine \& Pharmacotherapy, 63, 383-395.

Lechuga, I. L. M., Lenferink, A. T. M., Kooyman, R. P. H., Greve, J., 1995, Feasibility of evanescent wave interferometer immunosensors for pesticide detection: chemical aspects, Sensors and Actuators B, 24-25, 762-765.

Lever, J. H., 2002, Paget's disease of bone in Lancashire and Arsenic pesticide in cotton mill wastewater: A Speculative Hypothesis, Bone, 31(3), 434-436.

Manisankar, P., Viswanathan, S., Pusphalatha, A. M., Rani, C., 2005, Electrochemical studies and square wave stripping voltammetry of five common pesticides on poly 3,4-ethylenedioxythiophene modified walljet electrode, Analytica Chimica Acta, 528, 157-163.
Manisankar, P., Sundari, P. L. A., Sasikumar, R., Palaniappan, S. P., 2008, Electroanalysis of some common pesticides using conducting polymer/ multiwalled carbon nanotubes modified glassy carbon electrode, Talanta, 76, 1022-1028.

Perez- Ruiz, T., Martinez- Lozano, C., Tomas, V., Martın, J., 2005, High-performance liquid chromatographic assay of phosphate and organophosphorus pesticides using a post-column photochemical reaction and fluorimetric detection, Analytica Chimica Acta, 540, 383-391.

Radi, A., 2005, Accumulation and trace measurement of chloroquine drug at DNA-modified carbon paste electrode, Talanta, 65, 271-275.

Tuovinen, K., Paakkanen, H., Hänninen, O., 2000, Detection of pesticides from liquid matrices by ion mobility spectrometry, Analytica Chimica Acta, 404, 7-17.

Wu, H. Z., Lee, Y. C., Lin, T. K., Shih, H. C., Chang, F. L., 2009, Development of anamperometric microbiodetector for pesticide monitoring and detection, Journal of the Taiwan Institute of Chemical Engineers, 40, 113-122.

Yang, G., White, I. M., Fan, X., 2008, An opto-fluidic ring resonator biosensor for the detection of organophosphorus pesticides, Sensors and Actuators B, 133, 105-112.

Zejli, H., Hidalgo-Hidalgo, J. L., Naranjo-Rodriguez, I., Liu, B., Temsamani, K. R., Marty, J. L., 2008, Alumina sol-gel/sonogel-carbon electrode based on acetylcholinesterase for detection of organophosphorus pesticides, Talanta, 77(1), 217-221. 